\title{
Models of Pricing and Coordination in Dual-channel Supply Chain with Business Reputation
}

\author{
Hui Ma De-Li Yang Jian-Jun Wang \\ School of Management, Dalian University of Technology, Dalian, 116023, P. R. China \\ Email:dlutmahui@126.com; somdyang@sina.com.cn;wmeagle717@163.com
}

\begin{abstract}
In order to meet the needs of different customer, manufacturer opened online direct channel based on retail channel. In the case of co-existence of dual-channel distribution, a model is built to analyze pricing competitions between one manufacturer and one retailer under the manufacturer providing business reputation to the retailer in a dual-channel supply chain. By designing business reputation, we make retailer participate in the competition more actively in dual-channel supply chain, improved the system order quantity. Furthermore the equilibrium pricing strategies were given by the Stackelberg game theory. The final illustrated the validity of the model by a numerical example.
\end{abstract}

Keywords: supply chain management, dual-channel distribution, Stackelberg game

\section{Introduction}

As the increasingly maturity of Internet shopping platform and people's lifestyle changes, the rapid growth of the number of businesses that use the Internet is a prevalent phenomenon. And more and more consumers are shopping through the Internet. It can be demonstrated from the data that in China up to June 2009, the size of on-line shopping user group had grown to 878.8 million, and the entire turnover had reached 3.6 thousand billion RMB with a year-on-year growth of $22.9 \%$. The sales volume in France is up to 24.7 billion euros, with a growth of $33 \%$ and so on. Based on this background, increasing manufacturers are opening online direct sales channel, sell the goods to the consumer via online direct sales and retail stores (hereinafter referred to as dual-channel). Compared to traditional retail channel, dual-channel coexistence can reach potential markets which traditional retail channel can not reach, but at the same time, the dual-channel structure also makes the manufacture and the retailer forming transverse competition. Based on the situation, we designed a business reputation (or deferred payment) to make the retailer participate in the competition more actively, and we investigated the pricing policies and coordination condition in dual-channel supply chain, consisting of one manufacturer and one retailer, and drew qualitative insights based on a numerical analysis.

Currently, study on dual-channel supply chain is becoming a research hot spot in supply chain arena. Researchers pay attention to the problem using different models from a different perspective, [5-7] from the view of the impact and role of direct sales channel, and [8] from the models' separability and optimality considers the relation and existence conditions of equilibrium policies,[9] from 
the industry characteristics consider the optimized ordering strategy and cooperative conditions. In the paper [10], the retail channel and direct channel are compared. In the paper [11], [12-14] pricing and contracts coordination in dualchannel supply chain have been studied respectively.

Literatures above mostly researched on pricing coordination issue under promotional efforts of retailers or different brand loyalty in dual-channel supply chain. Research on manufacturer providing business reputation (allow retailer to delay payment) in dual-channel supply chain is still very rare. Paper [15] researched the revenue-sharing contract based on the business reputation in the traditional retail channel. There is no consideration to the dual-channel supply chain coordination.

\section{Dual-channel Supply Chain Coor- dination Model Based on the Busi- ness Reputation}

In the supply chain consisting of one supplier and one retailer, manufacturer provides retailer with business reputation, that is, the manufacture allows the retailer delay in payment. By reducing the cost of retailer funds attracts retailer to increase orders, furthermore, expand sales and avoids the retailers out of competition when direct channel exists. This is equivalent to the manufacturer provides interest-free loan to the retailer. The retailer can use these funds to obtain the appropriate return on investment. If expands sales, the manufacturer's profit will also increase. However, the funds of the manufacturer will be occupied by the retailer. Manufacturer will increase the opportunity cost correspondingly. The longer the credit period, the greater the attractiveness to retailer, manufacturer increases the cost more. We assume the product is short-life cycle. The production capacity of the manufacturer is large enough.

Similar to the paper [11], we follow the price-sensitive demand function in dualchannel supply chain. $d_{e}, d_{t}$ respectively donate direct channel and traditional retail channel demand

$$
\begin{aligned}
& d_{e}=\left(a_{e}-b p_{e}\right)+v\left(p_{t}-p_{e}\right) \\
& d_{t}=\left(a_{t}-b p_{t}\right)+v\left(p_{e}-p_{t}\right)
\end{aligned}
$$

Where $a_{i}$ denotes the demand of market benchmarks in channel $i,(i=e$ denotes the direct channel, $i=t$ denotes the traditional channel), $p_{t}$ denotes the retail price, $p_{e}$ denotes the direct price, $b$ denotes price elasticity of demand $(b>0), v$ denotes the degree of proliferation, which describes diffusion degree caused by the price differences of channels.

In the dual-channel supply chain, the profits of manufacturer and retailer are

$$
\begin{gathered}
\pi_{m}=\left(p_{e}-c\right) d_{e}+\left(w-c-c i_{m} t\right) d_{t} \\
\pi_{r}=\left(p_{t}-w+p_{t} i_{r} t\right) d_{t}
\end{gathered}
$$

If the supply chain is a system which the manufacturer is the leader, and the retailer is the follower, then the manufacturer and the retailer construct a Stackelberg game model. Given the manufacturer's decision variable $\left(w, p_{e}\right)$, retailer develops appropriate decision $\left(p_{t}, d_{t}\right)$. So the equilibrium solutions are followings.

$$
\begin{aligned}
& p_{e}^{*}=a_{t} v\left(4+5 i_{r} t\right) \phi+b c v\left(8+7 i_{r} t\right) \phi \\
& +a_{t} i_{r}^{2} t^{2} v \phi-(b+v) c i_{m} i_{r} t^{2} v \phi \\
& +\left(4 a_{e} b+4 a_{e} v+4 b^{2} c\right)\left(1+i_{r} t\right) \phi
\end{aligned}
$$




$$
\begin{aligned}
& w^{*}=4 a_{t} b^{2}\left(1+i_{r} t\right) \mu+4 b^{3} c\left(1+i_{m} t\right) \mu \\
& +a_{t} v^{2}\left(4+3 i_{r} t\right) \mu+2 b^{2} c v\left(6+i_{r} t\right) \mu \\
& +2 a_{e} i_{r} t v^{2}(b+1) \mu+8 a_{t} b v \mu+8 b c v^{2} \mu \\
& +4 a_{e} v(b+v) \mu-c i_{m} i_{r} t^{2} v^{2}(b+v) \mu \\
& p_{t}^{*}=3 b^{2} c t v\left(i_{r}+2 i_{m}\right) \varphi /(b+v) \\
& +\left(6 a_{t} b^{2}+4 a_{t} v^{2}+12 a_{t} b v\right)\left(1+i_{r} t\right) \varphi /(b+v) \\
& +\left(4 a_{e} v+8 b c v+3 a_{e} i_{r} t v-c i_{m} i_{r} t^{2} v^{2}\right) \varphi \\
& +b c t v^{2}\left(4 i_{m}+5 i_{r}\right) \varphi /(b+v) \\
& +2 b^{3} c\left(1+i_{m} t\right) \varphi /(b+v)
\end{aligned}
$$

$d_{t}^{*}=2 a_{t} b^{2}\left(1+i_{r} t\right) \varphi-b c i_{m} t v(6 b+4 v) \varphi$ $-2 b^{3} c\left(1+i_{m} t\right) \varphi+\left(b^{2} c v+4 a_{t} b v-4 b^{2} c v\right) i_{r} t \varphi$ $+\left(a_{e} v^{2}+a_{t} v^{2}+a_{e} b v+2 b c v^{2}\right) i_{r} t \varphi$

Where

$$
\begin{aligned}
& \varphi=1 /\left(8 b^{2}\left(1+i_{r} t\right)+16 b v\left(1+i_{r} t\right)-i_{r}{ }^{2} t^{2} v^{22}\right) \\
& \mu=\varphi\left(1+i_{r} t\right) /(b+v)
\end{aligned}
$$

From Equation (5-8), there are the equilibrium profits of manufacturer and retailer in decentralized decision-making $\pi_{m}^{*}, \pi_{r}^{*}$; and by $\pi_{s}^{*}=\pi_{m}^{*}+\pi_{r}^{*}$,we can get the equilibrium profit of the supply chain system $\pi_{s}^{*}$ in decentralized decisionmaking.

If the supply chain is vertically integrates system, the total system profit is

$$
\pi=\left(p_{e}-c\right) d_{e}+\left(p_{t}+p_{t} i_{r} t-c-c i_{m} t\right) d_{t}
$$

From the first-order condition, we can see the optimal parameters in centralized decision-making system are followings.

$$
\begin{aligned}
& p_{s e}{ }^{*}=a_{t} v\left(2+3 i_{r} t\right) \phi+b c v\left(4+3 i_{r} t\right) \phi \\
+ & a_{t} i_{r}^{2} t^{2} v \phi-(b+v) c i_{m} i_{r} t^{2} v \phi \\
+ & \left(2 a_{e} v+2 a_{e} b+2 b^{2} c\right)\left(1+i_{r} t\right) \phi \\
p_{s t}{ }^{*}=\left(2 a_{t} b+2 a_{t} v\right)\left(1+i_{r} t\right) \phi & (11) \\
+ & \left(2 b^{2} c+4 b c v\right)\left(1+i_{m} t\right) \phi \\
+ & {\left[a_{e} v\left(2+i_{r} t\right)+b c i_{r} t v-c i_{m} i_{r} t^{2} v^{2}\right] \phi }
\end{aligned}
$$

Where

$\phi=1 /\left(4 b^{2}\left(1+i_{r} t\right)+8 b v\left(1+i_{r} t\right)-i_{r}^{2} t^{2} v^{22}\right)$

Then the optimal profit of the supply chain system $\pi^{*}$ is

$$
\begin{aligned}
& \pi^{*}=\left(i_{m}-i_{r}\right) v^{2} \phi\left[\left(a_{e}+a_{t}\right) c i_{r} t^{2}-2 b c^{2} i_{m} t^{2}\right] \\
& +\left(4 a_{t} b c i_{m} t-a_{e}^{2}\right)\left(1+i_{r} t\right) v \phi \\
& +a_{t} b c i_{r} t\left(3-i_{r} t\right) v \phi-\left(a_{t}+a_{t} i_{r} t\right)^{2} v \phi \\
& +b^{2} c^{2} i_{m} t^{2} v\left(i_{r}-3 i_{m}\right) \phi-b^{3} c^{2} \phi\left[\left(1+i_{m} t\right)^{2}+i_{r} t\right] \\
& +a_{e} b c i_{r} t v\left(5+i_{m} t\right) \phi-a_{t}^{2} b\left(1+i_{r} t\right)^{2} \phi \\
& +4\left(a_{e}+a_{t}\right) b c v \phi-a_{e} a_{t} i_{r} t v\left(3+i_{r} t\right) \phi \\
& +4 b^{2} c^{2}\left(1+i_{m} t\right) v \phi+\left(2 b^{2} c^{2} i_{r} t+2 a_{e} a_{t}\right) v \phi \\
& +\left(2 a_{t} b^{2} c i_{m} t+2 a_{t} b^{2} c-a_{e}^{2} b+2 a_{e} b^{2} c\right)\left(1+i_{r} t\right) \phi
\end{aligned}
$$

\section{The Condition of Nodes Coordina- tion in Dual-channel Supply Chain under Business Reputation}

In traditional environmental, supply chain coordination often avoid 'double marginalization' through adjusting the profits conflict between the upstream and downstream nodes enterprises. This paper coordinates the supply chain by adjusting pricing. As $\pi_{s}^{*}>\pi_{m}^{*}+\pi_{r}^{*}$, we can see that the total profit of the supply chain system in centralized decision-making is greater than that of in decentralized decisionmaking, therefore, making the optimal 
profit under the decentralized decisionmaking equal to the optimal profit under the centralized decision-making, must meet the optimal pricing policy equal. That is $p_{s e}^{*}=p_{e}^{*}$ and $p_{s t}^{*}=p_{t}^{*}$. Simultaneous equations (5)、(10) and (7)、(11). When the condition

$$
\begin{aligned}
& \left(2 b^{2} a_{t}+4 b v a_{t}\right)\left(1+i_{r} t\right)+a_{e}\left(i_{r} t v^{2}+b i_{r} t v\right) \\
& -b^{3} c\left(1+i_{m} t\right)-b^{2} c v\left(4+6 i_{m} t-i_{r} t\right) \\
& +2 b c t v^{2}\left(i_{r}-2 i_{m}\right)+a_{t} i_{r} t v^{2}=0
\end{aligned}
$$

is satisfied, the pricing equation is true. That is the dual-channel system can achieve pricing coordination and avoid the 'double marginalization'.

\section{Numerical Example}

In this section our objective is to draw qualitative insights based on a numerical analysis of our model in a dual-channel supply chain, when business reputation exists. We illustrate our results with the help of a selected numerical example. The parameters are $b=7, v=2, c=5$, $i_{s}=10 \%, i_{r}=50 \% \quad, \quad a_{e}=400$, $a_{t}=339$. When the credit cycle is different value in the interval $[1,12]$, we can obtain the relation graphs between credit cycle and other parameters.

Figure 1 and Figure 2 represent the effect of credit cycle on order quantity and equilibrium price, where the unit of credit cycle is month. As the credit cycle increases, both the direct price and wholesale price at equilibrium go up, and order quantity at equilibrium increase as well, but the retail price at equilibrium decreases.

Therefore, an increase in the retailer's credit cycle allows the retailer to decrease the retail price under the premise of expanding profit. At the same time, although the manufacture increases the wholesale price, the retailer still increases order quantity.

Another interesting observation from Figure 2 is that as the credit cycle increases, the wholesale price at equilibrium increases. Thus the wholesale price at equilibrium increasing leads to the direct channel sales volume reducing. So the manufacture's profit increases must root in the retailer order quantity increasing. That is the profit root in the retailer order quantity at equilibrium increases at a faster rate than the manufacturer loss in the direct price increases. Thus, it is indeed possible for the manufacturer to focus on increasing its credit cycle in order to be more profitable.

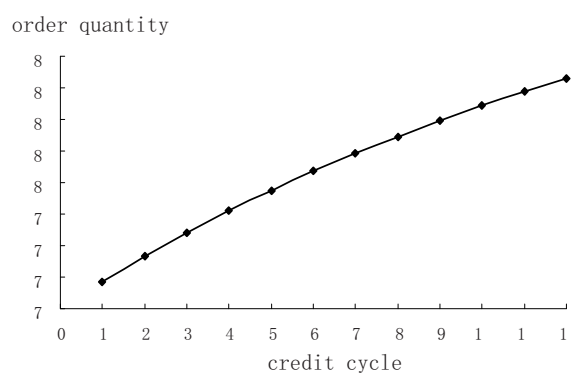

Fig. 1: The relation between credit cycle and order quantity.

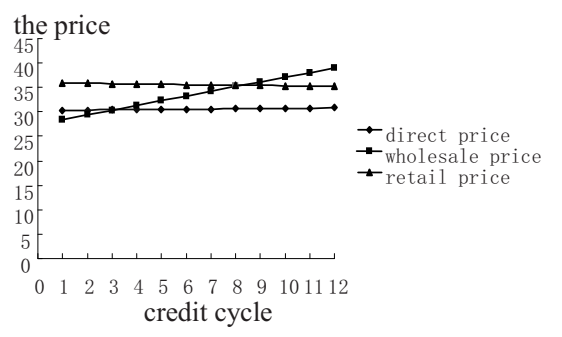

Fig. 2: The relation between credit cycle and sale price.

Figure 3 represents the relationship between wholesale price $w$ and order quantity $d_{t}$. When the wholesale price changes in a certain range, the order quantity remains unchanged. For example, when 
$w \in[27.2,27.8]$, order quantity remains at 68.5 units. As the wholesale price increases, order quantity also increases until it reaches the point of maximum demand, after that no matter whether the wholesale price increases or decreases, order quantity is maintained at the same point of maximum demand.

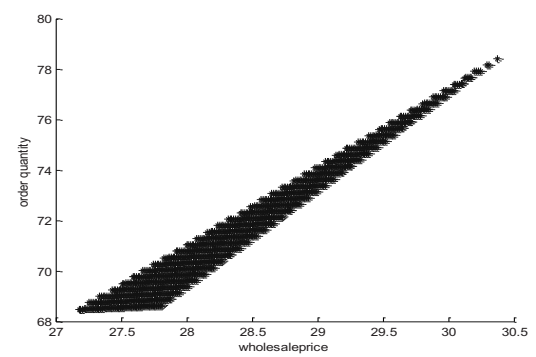

Fig. 3: The relation between wholesale price and order quantity.

\section{Conclusions}

Based on business reputation, we consider the optimal pricing strategies in dualchannel supply chain both in decentralized and centralized decision-making. Under the assumption of price-sensitive demand functions, we coordinate the supply chain by adjusting price. This work expands the study of traditional supply chain coordination based on business reputation. And our model differs from prior studies in the following areas: First of all, most of the studies about the business reputation or deferred payment have focused on traditional retail channel, but we consider the pricing policies of the supply chain in dual-channel environment. Another the research in dual-channel supply chain often gave a parameter (such as promotional efforts), instead, this paper establishes multiple parameters such as capital employed rate of manufacturer and return in investment rate of retailer, credit period and other parameters. It was closer to the actual analysis, coordinating the supply chain and ensure that the win-win situation of the channel members.

\section{Acknowledgments}

This work is supported by Major Program of National Natural Science Foundation of China (70890080, 70890083). The authors also gratefully acknowledge the helpful comments and suggestions of the reviewers, which have improved the presentation.

\section{References}

[1] R Amit and C Zott, "Value Creation in E-business," Strat. Mgmt. J., pp.493-520, 2001.

[2] H Yue and J J Liu, "Demand forecast sharing in a dual-channel supply chain," European Journal of Operational Research, pp.646-667, 2006.

[3] T Moriarty and U Moran, "Managing hybrid marketing systems," Harvard Business Review, pp.146-155, 1990.

[4] H A Niels, M Fleischmann and JAEEV Nunen, "E-fulfillment and multi-channel distribution - A review,"European J. Operational Research, pp. 339-356, 2008.

[5] A Tsay and N Agrawal, "Modeling conflict and coordination in multichannel distribution systems: a review," Chapter 13 in Supply Chain Analysis in the e-Business Era, Kluwer Academic Publishers, 2004.

[6] K Chiang, D Chhajed and J D Hess, "Direct Marketing, Indirect Profits: A Strategic Analysis of Dual-Channel Supply-Chain Design," Management Science, vol.49, pp. 1-20. 2003.

[7] Kumar and RR Ruan, "On manufacturers complementing the traditional retail channel with a direct online channel," Quantitative Market Economics, pp.289-323, 2006. 
[8] X Jia, H Li and X P Hu, "Equilibrium Policies Model of Ordering and Pricing in a Three-Tier Supply Chain Network," ICIC Express Letters, pp.1095-1100, 2010.

[9] D Zhao, Z Li and M Liu, "Optimized Ordering Strategy for Food Supply Chain with Bidirectional Options," IJICIC, Information \& Control, pp. 3971-3982, 2009.

[10]Q Yao and J J Liu, "Competitive pricing of mixed retail and e-tail distribution channels," Omega, pp. 235247, 2005.

[11]Hisashi, D Q Yao and J J Liu, "Pricing policies under direct vs. indirect channel competition and national vs. store brand competition," European J. Operational Research, vol. 180, pp. 262-281, 2007.

[12]N Yan, X Y Huang and B Liu, "Stackelberg game models of supply chain dual-channel coordination in emarkets," Chinese J. Management Science, pp.98-102, 2007.

[13] L Yan, "Profit sharing and firm performance in the manufacturer-retailer dual-channel supply chain," Electron Commerce Research, pp. 155-172, 2008.

[14]P Cachon and MA Lariviere, "Supply Chain Coordination with Revenue-Sharing Contracts:Strengths and Limitations," Management Science, pp.30-44, 2005.

[15] P Yu, X Y Huang and R Z Qiu, "Supply chain coordination and revenue-sharing contract based on trade credit," Operations Research \& Management Science, pp.42-46, 2009. 